\title{
(t)
}

\section{REFLEXÕES CRÍTICAS SOBRE AS POLÍTICAS DE GERAÇÃO DE TRABALHO E RENDA NO BRASIL}

\author{
CRITICAL REFLECTIONS ON TRABAJO CREATION POLICIES \\ AND INCOME IN BRAZIL
}

\section{Aline Fardin Pandolfi'}

\section{RESUMO}

Este artigo busca refletir criticamente sobre a implementação das políticas de geração de trabalho e renda no Brasil. Para isso, realizamos um recorte metodológico que articula a configuração do trabalho no modo de produção capitalista, o processo de superexploração do trabalho, ao qual estão submetidas às classes trabalhadoras brasileiras e, a configuração das políticas sociais no Brasil em período neoliberal. Ao final, refletiremos sobre as políticas de geração de trabalho e renda, as quais estão sendo implementadas no Governo do Partido dos Trabalhadores (PT) com o intuito de responder às demandas imediatas de trabalho e renda, garantindo, sobretudo, a acumulação do capital no país.

Palavras chave: Trabalho. Superexploração do trabalho. Políticas de geração de trabalho e renda.

\section{ABSTRACT}

This article seeks to critically reflect on the implementation of the generation of employment and income policies in Brazil. For this, we conducted a methodological approach that articulates the work setting in the capitalist mode of production, the exploitation process of the work, which is subject to Brazilian working class and the setting of social policies in Brazil in neoliberal

\footnotetext{
1 Doutoranda em Política Social pela Universidade Federal do Espírito Santo (UFES) (2013-2017), sob orientação do Prof. Dr. Paulo Nakatani. Bolsista da Coordenação de Aperfeiçoamento de Pessoal de Nível Superior (CAPES). Mestre em Política Social pela Universidade Federal do Espírito Santo (UFES) (2010). Professora do curso de Serviço Social da Faculdade Católica Salesiana de Vitória-ES.
} 


\section{temporolis}

period. Finally, reflect on the generation of employment and income policies that are being implemented in the government of the Workers Party (PT) in order to meet the immediate demands of work and income, ensuring, above all, the accumulation of capital at the country.

Keywords: Work. Exploitation work. Generation of employment and income policies.

Submetido: 14/09/2015.

Aceito: 28/11/2015.

\section{Introdução}

Partiremos de uma breve reflexão sobre a categoria trabalho e sua configuração na sociedade capitalista e, de seu meandro, iremos aprofundar outra categoria da tradição marxista a esta primeira vinculada, a superpopulação relativa (estagnada, flutuante e latente). Isso porque esta última é menos difundida nas publicações relativas ao Serviço Social e, sobretudo, imprescindível para nossa discussão sequencial. Também nesta primeira parte caracterizaremos o processo de exploração do trabalho (mais-valia), a lei geral da acumulação capitalista e a "questão social" na contemporaneidade.

Posteriormente, buscaremos caracterizar o intercâmbio desigual que desfavorece os países latino-americanos, inclusive o Brasil, na economia capitalista mundial e o processo de deslanche e conformação da nossa economia mediante a denominada superexploração do trabalho evidenciada por Marini (2000). Perante essa caracterização mais geral, será possível compreender como se constituíram e a atualidade das políticas sociais brasileiras, as quais estão orientadas principalmente pelos parâmetros internacionais do capital para a América Latina. Aqui, destacaremos as principais políticas e direitos destinados ao trabalho que se conformaram ao longo da história do Brasil e contextualizaremos suas tendências no contexto neoliberal.

Por último, refletiremos sobre as políticas de geração de trabaIho e renda atualmente em vigor no Brasil, com o intuito de mostrar suas características principais e como estão vinculadas aos interesses do capital em etapa neoliberal - considerando as intenções deste para a América Latina. Destacaremos essas políticas no Governo PT, o qual aglutinou interesses diversos durante seu período eleitoral, especialmente nos dois mandatos do Presidente Luiz Ignácio Lula da Silva e no primeiro de Dilma Roussef.

As políticas de geração de trabalho e renda do período atual estão destinadas principalmente ao empreendedorismo e as ativida- 


\section{tempordils}

des denominadas de auto emprego, sendo desenvolvidas por várias frentes, como através do: Programa de Geração de Emprego e Renda destinado a concessão de crédito; Programa Nacional do Microcrédito Produtivo Orientado (PNMPO), também destinado a concessão de crédito; e a Economia Solidária. Além destes, apontaremos reflexões sobre o funcionamento do Sistema Nacional de Emprego (SINE), que objetiva encaminhar trabalhadores(as) desempregados(as) para o mercado de trabalho; e os objetivos do Plano Nacional de Qualificação (PNQ) que detalha a política voltada para qualificação profissional.

Essas políticas são implementadas com a intenção de amenizar o cenário de ampliação do desemprego e/ou de uma nova conformação da superpopulação relativa conforme caracterizamos no texto, buscando assim, garantir o controle e hegemonia do capital na luta de classes e, concomitantemente, a reprodução da força de trabalho. O que se evidencia na atualidade, é que as políticas e programas destinados a geração de trabalho e renda no Brasil buscam atender aos objetivos do capital para a América Latina, sendo priorizados programas que reduzam os custos do capital, por meio da flexibilização das relações de trabalho e fortalecimento das atividades voltadas para o auto emprego que, em grande parte, se configuraram no setor informal da economia.

Soma-se a esse contexto uma questão política fundamental, o fato de o Partido que conduz as mudanças atuais haver se constituído e sido eleito com base em amplo apoio popular e de grande parte da esquerda deste país. Este aspecto tem dificultado a atual organização dos(as) trabalhadores(as) brasileiros(as) no campo da esquerda, há um cenário político de descrença na organização partidária, na esquerda, na luta por direitos e, sobretudo, na luta revolucionária.

\section{A configuração do trabalho no modo de produção capitalista}

De acordo com Lukács (1979), independente da forma de sociedade em vigor, o trabalho é central na produção e reprodução das relações sociais, é constituidor do ser social o processo de transformação da natureza com o intuito de abastecer as necessidades humanas, ao mesmo tempo em que, modifica e transforma também o homem. O "trabalho", enquanto produtor de "valor de uso" esteve e estará presente em todas as formas de sociedade, sendo a fonte de riqueza e da cultura da sociedade, Marx (2008). 


\section{temporollis}

Contudo, no modo de produção capitalista, o "trabalho" assume também o caráter de "trabalho abstrato", pois no mercado são igualados produtos de trabalhos úteis diferentes, evidenciando que nesse modo de produção o trabalho assume nova roupagem, além de ser produtor de produtos que servem à utilização humana, estes são produzidos com o intuito de serem trocados no mercado, denominando-se "mercadorias". Aqueles que possuem os meios para a produção das "mercadorias" contratarão, por algum preço, aqueles que nada possuem nessa sociedade a não ser sua "força de trabalho", a qual também é vendida como as outras mercadorias nessa sociedade. Os detentores dos meios necessários à produção representam a menor parcela populacional da sociedade. A classe capitalista ou burguesa, garante sua elevada condição de vida ${ }^{2}$ através da exploração do trabalho, que se materializa no desgaste, consumo da força de trabalho durante o processo produtivo. ${ }^{3}$

O trabalho nessa sociedade se depara com essa relação de exploração, em que a riqueza erguida socialmente não é apropriada por aqueles que a produzem, mas transferida para os detentores dos meios de produção. A classe trabalhadora possui um preço no mercado de trabalho denominado salário que, como o preço de qualquer mercadoria, sofre influência das oscilações do mercado, sendo normalmente um preço menor que o "valor" do seu trabalho (MARX, 2008).

Entretanto, mesmo se o trabalhador obtivesse uma remuneração, salário, correspondente ao "valor" do seu trabalho a exploração se manteria, pois, o "valor" refere-se à remuneração pelo trabalho que equivalha à aquisição da "cesta de consumo dos trabalhadores", que permita o acesso aos serviços e bens necessários ao reabastecimento e reprodução da força de trabalho. ${ }^{4} \mathrm{O}$ valor dessa cesta de consumo é sempre inferior ao que produz os trabalhadores em toda sua jornada de trabalho, se não o fosse, o capitalista não contrataria essa força de trabalho, já que o sentido da contratação está aqui, no fato

2 Diferente da "cesta de consumo dos trabalhadores" são os bens consumidos pela parcela detentora da riqueza na sociedade capitalista, os "bens suntuários da burguesia". (CARCANHOLO, 2007; MARX, 2008).

3 A citada relação de exploração é explicada pelo conceito de "mais-valia" de Marx.

4 A reprodução da força de trabalho significa também a reprodução dos dependentes desse trabalhador, sua mulher e filhos, garantindo a reprodução da força de trabalho futura (CARCANHOLO, 2007; MARX, 2008). 


\section{tempordils}

de a maior parte da produção, diária, semanal ou mensal, ser apropriada pela burguesia, mesmo se os salários forem correspondentes ao valor, o trabalhador é quem produzirá a parcela correspondente a sua remuneração (trabalho necessário) e a parcela excedente (trabaIho excedente), a "mais-valia" do capitalista.

É o processo de exploração do trabalho e suas consequências que evidenciará a "questão social", compreendida através da tradição marxista5.

Na passagem da consciência histórica de classe, quando as classes trabalhadoras se corroboram enquanto grupo na perspectiva revolucionária socialista e deixa de ser uma "classe em si" para tornarse "classe para si", evidencia-se a compreensão da "questão social" enquanto mote diretamente vinculado e submetido ao modo de produção capitalista. Dessa forma, a sua superação implicaria a necessária ultrapassagem do capitalismo e a construção de uma sociedade sem exploração de classes e outras formas de opressão (PAULO NETTO, 2005).

É nas obras de Marx que se denuncia a origem e se justifica a permanência da "questão social", e, apesar de o autor não ter utilizado esse termo, é com fundamento na contradição capital/trabalho, da "lei geral da acumulação capitalista", atreladas as mediações que possibilitam compreender os demais fenômenos presentes nessa sociedade, que o termo "questão social" é utilizado por diversos autores $^{7}$ do Serviço Social.

Ao discorrer sobre a "lei geral da acumulação capitalista", Marx aponta a permanência da desigualdade social nesse modo de produção, o aprofundamento da "concentração e centralização" de capitais concomitante ao empobrecimento dos(as) trabalhadores(as). Os salários tendem a baixar gradativamente e a distanciar-se cada vez mais de seus respectivos valores, submetendo os trabalhadores a condições de vida cada vez piores. De acordo com Marx (1996, p.172),

5 É importante frisar que existem constatações sobre a "questão social" em outros campos teóricos.

6 Classe que se percebe enquanto potência revolucionária, que passa a se organizar na perspectiva da transformação social rumo ao fim do capitalismo e à construção do socialismo.

7 Como José Paulo Netto e Marilda Vilela Iamamoto. 


\section{temporollis}

“[...] determinada a soma de riqueza que se deve distribuir entre os assalariados, a parte que toca a cada um é demasiadamente pequena, e ocorre que a miséria passa a ser um fato, não da ordem social, mas da ordem natural do sistema capitalista." Naturalizar os fenômenos inerentes ao capitalismo ocorre com todas as manifestas expressões da "questão social", como o aumento da violência, da pobreza, do desemprego, os quais são naturalizados ao longo dos anos e aparecem como parte integrante de qualquer sociedade, mistificando sua essência estruturante (IAMAMOTO, 2008).

Recentemente, a "questão social" está ainda relacionada ao período de máximo fetiche do capital, em que os lucros pela via da esfera fictícia, "[...] conduz [a máxima] banalização da vida humana, à descartabilidade e indiferença perante o outro, [...] a radicalidade da alienação e a invisibilidade do trabalho social - e dos sujeitos que o realizam [...]" (IAMAMOTO, 2008, p. 29). Assim, se aprofunda o fetichismo sobre a origem do valor, da mais-valia, da relevância do trabalho, da sua centralidade na produção na riqueza social e no processo de constituição da vida humana e, se apresenta uma nova mística em relação à contradição capital/trabalho: a falsa ideia da não necessidade de exploração direta pela via do trabalho.

Nessa mesma perspectiva, a demanda do capital por mais trabalho não requer necessariamente um aumento quantitativo no número de trabalhadores partícipes na produção, devido a possibilidade de se ampliar a extração da mais-valia pela extensão da jornada de trabalho ou através de sua intensificação. De acordo com Marx (1996, p.181), o "[...] capital adicional formado no processo da acumulação, quanto maior se torna, cada vez menos trabalhadores empregam." É nesse contexto que Marx desenvolve o conceito de "superpopulação relativa", relativa porque não depende apenas do aumento real do número de trabalhadores, mas também "[...] das condições do capital social, que passa a prescindir de uma parte mais ou menos considerável de seus operários, gerando um contingente de reserva". Por isso, também utiliza a expressão "exército industrial de reserva", que é essencialmente compreendido devido as formas da "superpopulação relativa".

A "superpopulação relativa" assume três formas: a flutuante, a latente e a estagnada. A denominada "superpopulação relativa flutuante" refere-se ao grupo de trabalhadores que ora estão empregados, ora estão desempregados, que oscilam/flutuam no mercado de 
trabalho. Este grupo está à mercê da necessidade de contratação das indústrias e instituições, conforme o ramo de atividade para a qual estão habilitados. Já a "superpopulação relativa latente" refere-se ao grupo de trabalhadores do campo que ao longo do capitalismo permanecem na eminência de migrar para as cidades e se inserir no mercado de trabalho industrial, deslumbrados pela possibilidade de acesso a melhores condições de vida. A história registra larga escala do denominado êxodo rural, especialmente nos períodos de início e expansão da indústria nos diversos países capitalistas. A "superpopulação relativa estagnada" refere-se a parcela da população que sobrevive em condição de pobreza recorrente, distanciada do acesso aos serviços e aos bens de consumo mais indispensáveis, caracteriza esse grupo o maior tempo de trabalho possível aliado aos mais baixos salários, entre eles registra-se o maior número de mortes, bem como de nascimentos, devido à própria condição de sobrevivência à revelia a qual estão expostos.

Há ainda o mais profundo sedimento da superpopulação relativa, que vegeta no pauperismo. Este grupo está composto por: trabalhadores aptos ao trabalho, porém não inseridos; órfãos e crianças indigentes, os quais possuem grande possibilidade de ampliar as "fileiras" do exército industrial de reserva; e por trabalhadores inválidos, tidos como "peso morto do exército industrial de reserva". Estes últimos custeados fundamentalmente pelos trabalhadores que mantém uma relação salarial - este custeio atualmente está configurado pela forma de impostos pagos para garantir os fundos na área da assistência, aposentaria e pensões.

\section{Inserção internacional e política social no Brasil}

A inserção do Brasil na conjuntura capitalista mundial foi similar a dos demais países da América Latina, em um primeiro momento, diretamente explorado pela relação colônia/metrópole. Posteriormente e, até o período atual, o Brasil mantém uma relação de subordinação aos ditames do grande capital dos países centrais e dos organismos multilaterais. Ao longo da história e da expansão das relações internacionais, o Brasil e outros países latino-americanos de origem agropecuária cumpriram a função de subsidiar com meios de subsistência os trabalhadores(as) dos primeiros países industrializados do mundo.

De acordo com a tese de Marini (2000), os países da América 


\section{temporollis}

Latina cumprem o papel de aumentar a "mais-valia relativa" dos países centrais, devido a sua própria função na divisão internacional do trabalho de produtores de bens primários exportados para aqueles países. A exportação de bens primários possibilita o acesso dos(as) trabalhadores(as) dos países centrais a uma cesta de consumo de mais baixo valor e mais baixo preço, o que reduz o tempo de trabalho socialmente necessário à reprodução da força de trabalho e, consequentemente, a extensão do tempo de trabalho excedente apropriado pelo capitalista. Esta relação se manifesta na redução dos salários e na apropriação da mais-valia relativa pelos capitalistas.

Este quadro se aprofunda na atual etapa da crise internacional em virtude da anunciada retração nos preços das commodities no mercado mundial, visto que novamente se reduz o preço da cesta de consumo dos(as) trabalhadores(as) e consequentemente o preço da força de trabalho daqueles países. Tal aspecto pode contribuir com a permanência da exploração da "mais-valia relativa" pelos países centrais e, consequentemente, auxiliá-los no enfrentamento aos impactos da crise. A mesma redução no preço das commodities no mercado mundial vem aprofundando os efeitos da crise junto aos países que dependem de sua exportação, como o Brasil.

Essa transferência de "mais-valia" da periferia para o centro é o fundamento do intercâmbio desigual, da troca desigual. Sendo que a reação da economia dependente é utilizar-se de outras estratégias do capital para garantir a exploração nos países periféricos. Nessa perspectiva, nos países latino-americanos se configura a denominada "superexploração do trabalho". Estes países, ao transferirem mais-valia aos países centrais, precisam estabelecer internamente um processo mais intenso de exploração do trabalho, com o intuito de manter um grau de acumulação também interno. Dessa forma, está caracterizado em países como o Brasil um processo de pagamento dos salários abaixo do valor da mercadoria força de trabalho, conforme aponta Marini (2000), há três mecanismos principais que configurarão a superexploração do trabalho: a intensificação do trabalho, a extensão da jornada de trabalho (que caracterizam um desgaste prematuro dos(as) trabalhadores(as)) e a expropriação de parte do trabalho necessário que serviria para a reposição da mercadoria força de trabalho. É evidente nestes países que os(as) trabalhadores(as) recebem salários abaixo de seus valores e que estes não possibilitam reproduzir sua força de trabalho e a de sua família. Além disso, nos 


\section{tempordilis}

países latino-americanos as condições de trabalho são mais precárias, as atividades que se realizam nestes países são marcadas pelo baixo desenvolvimento das forças produtivas e, não são acompanhadas de um aumento na produtividade o que, consequentemente, não amplia a possibilidade de acesso pelos(as) trabalhadores(as) a bens de consumo mais baratos.

É a partir dessa inserção do Brasil a nível internacional que é possível compreender a conformação das políticas sociais presentes hoje no país, inclusive as destinadas a geração de trabalho e renda, ponto principal deste artigo.

A política social brasileira é constituída distintamente da política social dos países centrais. O Brasil não vivenciou o período conhecido por Welfare State, entre a década de 1930 e 1970, quando se constituem as denominadas políticas sociais dos países centrais - em resposta à devastação da II Guerra Mundial, às manifestações da classe trabalhadora e à ameaça de revoluções de caráter socialista/comunista que vinham ocorrendo no mundo. Nesse mesmo período, o Brasil irá iniciar e consolidar a industrialização nacional, a qual se configura a partir da transferência de fluxo estrangeiro de capital, equipamentos e maquinários que já eram considerados obsoletos nos países centrais (CARVALHO, 2008; MARINI, 2000).

Diante deste cenário, concomitante ao surgimento da "questão social" e suas expressões no país, que se começa a constituir e implantar as primeiras políticas sociais no Brasil. É na denominada "Era Vargas" ${ }^{8}$ que se registrou o primeiro arcabouço legislativo em torno do trabalho, resultado do conflito capital/trabalho no início do processo de industrialização do país. Ao mesmo tempo, as mudanças inseridas atendiam principalmente aos interesses da elite nacional que emergia aliada aos representantes do grande capital internacional e precisava conter as contradições inerentes ao processo de produção industrialização, especialmente a evidência entre os polos riqueza/pobreza (CARVALHO, 2008).

Outro período em que ocorrem aprovações de legislação na área do trabalho é na Ditadura Militar (1964-1984). No Brasil, ao longo desses vinte anos são suspensos diversos direitos políticos e civis, ao mesmo tempo em que foram concedidos alguns benefícios sociais

8 Governo de caráter autoritário que se estendeu até 1945, inspirado no regime fascista. 


\section{temporollis}

vislumbrando a legitimidade do regime. Para isso, foram constituídos nesse período: o Instituto Nacional de Previdência Social (INPS); o Fundo de Garantia por Tempo de Serviço (FGTS) (em substituição ao direito à estabilidade de emprego após 10 anos de serviço); o Programa de Integração Social (PIS); o Programa de Formação do Patrimônio do Servidor Público (Pasep); o Fundo de Apoio ao Desenvolvimento Social (FAS); o Sistema de Indicadores Sociais. Criou-se ainda neste período o: Conselho Nacional de Política de Emprego, Conselho Federal de Mão-de-Obra, Ministério da Previdência e Assistência Social; e o Sistema Nacional de Empregos (SINE).

Já diante da desestabilidade do regime ditatorial em seus últimos anos, vários partidos são criados, dentre eles o Partido dos Trabalhadores (PT), em 1980. A diferença deste para os demais se refere à forma como foi constituído, não sendo dominado por membros da elite social e econômica, o PT surgiu de amplo movimento popular em reunião aberta, da qual participaram centenas de militantes. Nesse período, também foi fundada a Central Única dos Trabalhadores (CUT), e essa, junto com o PT, fortaleceu o movimento sindical e as reivindicações dos trabalhadores neste período (CARVALHO, 2008).

Em 1988 temos a aprovação da nova Constituição da República, a qual irá prever o trabalho, a educação, a saúde, a assistência e outros direitos sociais básicos. Contudo, dois anos após a aprovação desta Constituição temos o ingresso da perspectiva de Estado neoliberal, que já guiava a produção capitalista dos países centrais e que, na década de 1990, viria a ser disseminada para toda a América Latina mediante a adesão ao Consenso de Washington. ${ }^{9}$ Este processo volta a reforçar a relação de dependência e subordinação econômica e política estabelecida entre os países latino-americanos e os países centrais.

A perspectiva de Estado neoliberal é caracterizada pela retração dos investimentos na área social, que se configura na redução de

9 Sob direção do Fundo Monetário Internacional (FMI) e do Banco Mundial, o Consenso de Washington foi baseado em um texto do economista norteamericano John Williamson, o qual relacionou um conjunto de medidas que deveriam ser adotadas pelos países periféricos no intuito de superar dificuldades macroeconômicas. O postulado de dez medidas prevê: disciplina fiscal, redução dos gastos públicos, reforma fiscal, juros de mercado, câmbio de mercado, abertura comercial, investimento estrangeiro com eliminação de restrições, privatização de estatais, desregulamentação das leis econômicas e trabalhistas e direito à propriedade intelectual. 


\section{tempordilis}

investimentos nas políticas sociais, no processo de privatização de setores estatais, na redução de número significativo de postos de trabalho, no aumento do número de subempregos e de contratações temporárias, dentre outros. Essa perspectiva de Estado nasce aliada a um novo padrão de acumulação do capital, advindo da crise do padrão de produção fordista..$^{10}$ Este seguiu a "lei tendencial da queda da taxa de lucro" e findou seu período de crescimento ingressando no esgotamento de um ciclo que será caracterizado por uma crise.

Procede a esse padrão de acumulação o processo de Reestruturação Produtiva ou "Acumulação Flexível"." Conhecido também por padrão de produção toyotista ${ }^{12}$, tem por características principais: a flexibilização da produção, marcada pela adequação da produção à demanda do mercado; o controle da qualidade; as novas formas de gestão da força de trabalho, com o perfil do trabalhador polivalente, o que evidencia o cume da intensificação do trabalho nesse período; a inclusão do trabalhador enquanto parte da gestão, de forma manipulada; a flexibilização das relações de trabalho materializada no aumento dos contratos temporários; o aumento de empregos no setor de serviços e abrupta redução dos empregos formais/regulamentados; o retrocesso do poder sindical; a terceirização de parte das funções das empresas, o que implicou em um processo de horizontalização da cadeia produtiva, o que também implica em condições de trabalho mais precarizadas para os(as) trabalhadores(as) que não compõem as empresas centro.

Esse período de globalização é também diferenciado pelo predomínio do capital fictício em relação ao capital produtivo, pela prioridade da obtenção de lucros pela via da especulação, conforme

10 A produção fordista foi marcada pela produção e consumo de massa, por técnicas de trabalho repetitivas e de controle do tempo de produção, pela relação um homem uma máquina, dentre outros. Foi aliada da perspectiva do Estado de Bem-estar Social, que primava pela proteção social e pelo "pleno emprego", para que este possibilitasse o consumo de massa. Este padrão de produção nasce na Ford na década de 1920, mas se estende a todas as demais empresas e países da produção capitalista. Autores que tratam desse período e das mudanças nos padrões de acumulação são: Antunes (2007); Gounet (1999); Harvey (2007); dentre outros.

11 Expressão utilizada por Harvey (2007).

12 Devido a origem ter sido na fábrica da Toyota; é também conhecido por onhismo refere-se ao nome do Engenheiro que pensou esse padrão de acumulação, Taiichi Onho. 


\section{temporollis}

caracterizado por Carcanholo e Nakatani (1999 p. 2-3) de "[...] capital especulativo parasitário ${ }^{13}$ (forma particular mais concreta derivada do capital portador de juros)." Nesse período, o capital produtivo recebe menos investimentos, sendo esses destinados ao capital fictício, ao "capital especulativo parasitário". Essa forma de obter lucros dissimula a real origem do valor e da mais-valia, conforme apontamos no primeiro item deste texto.

Concomitante aos ganhos na esfera especulativa parasitária, o que se identifica nessa fase é a abrupta intensificação do trabalho, é a cooptação do trabalhador e de sua consciência pela fábrica, que passa a denominá-lo de "colaborador" e identificá-lo como "membro da família". Além disso, este trabalhador(a) é mais facilmente substituível dada a flexibilização nas relações de trabalho.

No Brasil, como se sabe, essas alterações se iniciam na década de 1990, em razão da forte crise econômica, marcada pela queda de 10\% do Produto Interno Bruto (PIB), recessão, queda dos salários e total descontrole inflacionário. As denúncias de corrupção somadas aos efeitos do confisco aumentaram as insatisfações populares, gerando o impeachment do Presidente Fernando Collor de Melo em 1992. Assume em seguida o Vice-Presidente Itamar Franco, que tendo Fernando Henrique Cardoso, no Ministério da Fazenda, implementam o Plano Real (BEHRING, 2003).

Após a instauração do Plano Real e o posterior governo de Fernando Henrique Cardoso (FHC) de 1995 a 2003, foi que, de acordo com Soares (2002, p.39), "[...] os contornos neoliberais do processo do ajuste brasileiro tornam-se mais nítidos, bem como as suas consequências econômicas e, sobretudo, sociais". Contudo, o controle inflacionário conseguido com o Plano Real - já distante dos brasileiros - e o mediano equilíbrio da moeda nacional, concedeu a FHC respaldo para promover no Brasil as ações demandadas pelo Consenso de Washington, com maior legitimidade.

13 De acordo com essa análise, o termo “capital especulativo parasitário" retrata de forma mais adequada o domínio do rendimento especulativo, dos lucros fictícios sobre os lucros provenientes da produção. O tradicional capital a juros e o capital comercial cumprem funções fundamentais junto à produção para garantir o excedente-valor, a mais-valia proveniente do capital produtivo. Já o "capital especulativo parasitário", é totalmente parasitário, não cumpre qualquer função junto à produção, por isso é real e não é, pois não corresponde a riqueza real produzida socialmente. 
Dessa forma, o Governo FHC foi o percursor da avalanche de privatizações de empresas estatais ${ }^{14}$, ampliou consideravelmente a participação do setor privado e reduziu os gastos públicos, especialmente nas políticas sociais (saúde, educação, assistência social). Este mesmo governo inaugurou a expansão da participação de instituições filantrópicas, não governamentais e/ou sem fins lucrativos na oferta de serviços previstos na Constituição como dever do Estado.

As políticas sociais em geral e, também as destinadas à área de geração de trabalho e renda, são marcadas nesse período pela focalização (voltadas para um público específico), pela descentralização (repasse de autonomia administrativa e financeira da esfera federal para as esferas estaduais e municipais), além de apresentarem as antigas práticas do país, o clientelismo, o autoritarismo e o paternalismo.

Após os oito anos de mandato do Governo FHC (PSDB $\left.{ }^{15}\right)$, tivemos oito anos de mandato de Luiz Ignácio Lula da Silva (PT), seguidos de quase 5 anos de Governo da Presidente Dilma Roussef (PT). Nestes, as políticas de trabalho e renda ganharam contornos específicos e seguem a "cartilha" neoliberal, conforme apontaremos a seguir.

\section{Políticas de trabalho e renda durante o governo PT}

Os trabalhadores(as) são a parcela dessa sociedade mais atingida pelas consequências da adesão ao ajuste neoliberal. O contexto pós 1990 no Brasil registra o agravamento da "questão social", que passa a manifestar novas expressões. Neste período há uma redução abrupta dos empregos na esfera produtiva, concomitante a opção pela flexibilização da produção e das relações de trabalho, além da prioridade dada aos investimentos no mercado financeiro. As consequências para os(as) trabalhadores(as) são: ampliação do "exército industrial de reserva"; redução da proteção social; ampliação dos grupos que passam a compor a "superpopulação relativa flutuante", devido a perda da relação de trabalho relativamente estável a

14 Em 1990 ocorreu a criação do Programa Nacional de Desestatização (PND), a privatização das empresas estatais federais e também estaduais foi intensa de 1991 até 2001. Ocorreram as vendas de empresas na área de siderurgia, fertilizantes, petroquímica, telecomunicações, no setor bancário, dentre outras. Até janeiro de 2002, 68 empresas haviam sido privatizadas, rendendo ao Governo Federal US\$ 28,58 bilhões. Para outras informações sobre esse contexto no Brasil, vide: Marques e Rego (2003).

15 Partido da Social Democracia Brasileira. 


\section{temporollis}

qual estavam submetidos; aumento da pobreza absoluta e relativa ${ }^{16}$, dentre outros. Diante deste quadro de ampliação da desestabilidade dos(as) trabalhadores(as) brasileiros(as) em relação a reprodução da vida através da relação salarial, são fortalecidas algumas iniciativas nos Governos de Lula e Dilma para incentivo da geração de trabalho e renda.

No contexto brasileiro, a crise econômica e o novo modelo de acumulação do capital (Acumulação Flexível), conduziu grande parcela dos trabalhadores para o denominado mercado informal de trabalho. Os(as) trabalhadores(as) informais ${ }^{17}$, em sua maioria, se constituem nos grupos de mais baixas remunerações do mercado de trabalho, remunerações imprecisas e imprevisíveis.

Desde a década de 1990 e com o aprofundamento da crise estrutural ${ }^{18}$ em 2015 no Brasil, acompanhamos uma ampliação progressiva da participação dos(as) trabalhadores(as) em atividades informais, as quais atingem em maior parte aqueles(as) com idade acima de 40 anos. Mesmo sabendo que há no campo da informalidade os que optam por essa forma de trabalho, vislumbrando ampliar sua renda e se abdicar da taxação de impostos, a grande parte dos trabalhadores(as) nesse campo são oriundos das fileiras do "exército industrial de reserva".

De acordo com o Dieese (2014) (19 $^{19}$ em 2014 o total de ocupados era de 16,392 milhões de pessoas, ou seja, entre opções de trabalho

16 A pobreza absoluta se refere ao total de carência de bens materiais e a pobreza relativa está vinculada ao aprofundamento da distância entre ricos e pobres, a desigualdade social.

17 É importante dizer que os trabalhadores(as) informais são compostos por grupos diversos. Alguns desses grupos, inclusive, possuem altos rendimentos e de fato optam por essa via de inserção no mundo do trabalho. No entanto, cabe reforçar que estes são exceções minoritárias diante de um vasto grupo que compõe a esfera informal. Para melhor avaliação, vide Tavares (2002).

18 Nossa compreensão acompanha a linha de pensamento de Mészáros (2011) de que se trata de uma crise estrutural do capital, iniciada na década 1970 no mundo, e que desde então mantém estagnados ou em declínio os lucros do capital.

19 A fonte de dados é o Departamento Intersindical de Estatística e Estudos Econômicos (DIEESE), devido a este órgão ser o que mais se aproxima da complexidade do mercado de trabalho e busca analisar Emprego e Desemprego, este aberto e oculto (por trabalho precário ou por desalento). Diferente do IBGE, que apenas considera a inserção por ocupação ou desocupação, sendo totalmente alheio à complexidade do mundo do trabalho deste modo de produção. 


\section{tempordils}

regulamentadas e informais. A População Economicamente Ativa (PEA) estimada era de 18,380 milhões de pessoas neste mesmo ano. Significa então que, do total de pessoas que estavam inseridas ou buscando inserir-se no mercado de trabalho, havia um total de quase 2 milhões que não estava no grupo de ocupados, considerando-se as cidades pesquisadas. ${ }^{20} \mathrm{~A}$ taxa de desemprego também se mantém consideravelmente alta, em torno de $9 \%$ nessas regiões metropolitanas, registrando-se a maior taxa de desemprego na cidade de Salvador, com $17,4 \%$, e a menor em Porto Alegre, com 5,9\%. Mesmo assim, foi anunciado em fins de 2014 que o Brasil apresentava o menor índice de desemprego registrado até então, segundo dados do Instituto de Geografia e Estatística (IBGE) a taxa de desocupação em junho de 2014 foi de $4,8 \%$. Já em julho de 2015 , o próprio IBGE registra uma ampliação da taxa de desocupação em virtude do aprofundamento da crise estrutural no país, até este período, esta taxa era de 7,5\%.

Segundo dados da Relação Anual de Informações Sociais (RAIS), registra-se uma ampliação progressiva dos vínculos formais de trabalho entre 2003 e 2007, ampliando-se em 64\%. Já no ano de 2008, também devido ao anúncio midiático de crise internacional, há uma retração dos empregos formais da ordem de $25 \%$ em relação a 2007. Entre 2009 e 2011 há uma nova expansão dos vínculos formais de trabalho, que voltam a se retrair entre 2011 e 2012, registrando uma queda abrupta no ano de 2014 da ordem de $79 \%$ em relação ao ano de 2011. O número de vínculos formais em 2014 chegou a um quantitativo inferior ao ano de 2003. Se considerarmos que anualmente o número de pessoas em idade para trabalhar se amplia, proporcionalmente, mais pessoas vêm a incorporar o exército industrial de reserva do país. Portanto, do ponto de vista da aparência, houve uma expansão nas ocupações, mas na essência, há uma progressiva retração dos empregos formais no país, se compararmos os anos anteriores e, uma tendência a se ampliar o exército industrial de reserva nacional (BRASIL, 2015a).

Até julho de 2015 foi registrada uma renda média mensal de $\mathrm{R} \$ 2.170,70$, sendo este $2,4 \%$ abaixo do apurado em julho de 2014 (R\$ 2.223,87), segundo dados do IBGE (2015). Ainda de acordo com o DIEESE (2015), em julho de 2015 o salário mínimo necessário aos traba-

20 A pesquisa deste Departamento contempla às cidades de: Salvador, Porto Alegre, Recife, Belo Horizonte, São Paulo e Distrito Federal. A pesquisa é de Emprego e Desemprego no mercado de trabalho metropolitano. 


\section{temporollis}

Ihadores(as) brasileiros(as) seria em média de $\mathrm{R} \$ 3.325$, 37 para manter a reprodução de um trabalhador(a) e sua família. Dessa forma, é evidente no caso brasileiro a tese sustentada por Marini (2000), pois a remuneração da força de trabalho no Brasil não permite o acesso a bens de consumo básicos à reprodução desta força de trabalho, é generalizado o pagamento de salários abaixo do seu valor.

Objetivando minimizar os impactos advindos do conflito capital/trabalho, o Estado brasileiro em face ao molde neoliberal orquestrado pelo Governo PT, inventa e reinventa programas e políticas no campo da geração de trabalho e renda para inserir, por alguma via, os(as) trabalhadores(as), de forma que garanta o ciclo de rotação do capital e a extração de mais-valia relativa e absoluta. Mais-valia essa destinada aos países centrais e a elite nacional, o que só pode se realizar com o aprofundamento da intensificação do trabalho, prolongamento da jornada de trabalho e expropriação de parte do trabalho necessário.

Ainda no Governo FHC foram criados alguns programas com a intenção de amenizar ou mistificar o quadro de desemprego, como o: Programa Nacional de Formação Profissional (PLANFOR), Programa de Geração de Emprego e Renda (PROGER), Programa de Emprego (PROEMPREGO) e as iniciativas de empréstimos do Banco Nacional de Desenvolvimento Social (BNDES), estes voltados ao empreendedorismo.

Atualmente, a nível nacional, é através dos recursos do Fundo de Amparo ao Trabalhador (FAT) que o governo disponibiliza, para as políticas ativas e passivas vinculadas ao Sistema Público de Emprego e Renda, a maior parte do subsídio para a execução das ações. O referido fundo é gerido pelo Conselho Deliberativo do Fundo de Amparo ao Trabalhador (CODEFAT) ${ }^{21}$.

Dentre as políticas de geração de trabalho e renda, os programas e linhas de crédito são priorizados. As linhas de financiamento

21 O CODEFAT possui representação dos empregadores - indicados pelas respectivas confederações - e, representação dos trabalhadores - indicados pelas centrais sindicais e confederações dos trabalhadores -, ambos em igual número. Também compõe este conselho um representante do Ministério do Trabalho, um representante do Ministério da Previdência e Assistência Social e um representante do BNDES. Outras informações sobre o CODEFAT, vide Lei $n^{\circ} 7 \cdot 998 / 1990$, a qual regula seu funcionamento. 


\section{tempordils}

também são destinadas prioritariamente a população mais pobre, que busca na informalidade alternativa a situação de pertencimento à superpopulação relativa estagnada. Assim, financia-se o autoemprego para minimizar, ao mesmo tempo em que incorre em reconhecer, a impossibilidade de vincular parte da população aos empregos formais e na esfera produtiva.

Uma das frentes de atuação é o Programa para Geração de Emprego e Renda. Este se constitui de "[...] um conjunto de linhas de crédito disponíveis para interessados em investir no crescimento ou modernização de seu negócio ou obter recursos para o custeio de sua atividade." (BRASIL, 2014)

Outro programa é o Programa Nacional do Microcrédito Produtivo Orientado (PNMPO), que visa incentivar a geração de trabalho e renda entre os microempreendedores populares. Este programa se refere a empréstimos disponibilizados pelas agências de financiamento do governo, destinados a microempreendedores, sendo que "[...] são considerados micro-empreendedores populares as pessoas físicas e jurídicas empreendedoras de atividades produtivas de pequeno porte, com renda bruta anual de até $\mathrm{R} \$ 120$ mil”, conforme previsto no no Decreto n. 6.607/2008.

É importante evidenciar que o Estado tem privilegiado declaradamente atuações no âmbito do próprio negócio, do empreendedorismo e do autoemprego, alternativas que coadunam com a perspectiva neoliberal e que são implementadas sob a lógica da "saída única" para enfrentar o aumento do desemprego estrutural, uma das consequências da crise econômica estrutural, deflagradas na década de 1980 e 1990 no Brasil (e 1970 no mundo). Isso para enfrentar o quadro de eliminação de postos de trabalho formais, de ampliação do exército industrial de reserva e extensão da superpopulação relativa estagnada e flutuante, que gera um aprofundamento da pobreza absoluta e relativa do país. Essas consequências levam o Governo a pensar estratégias que mantenham em ascensão a rotação do capital, ao mesmo tempo em que busca desmobilizar as possibilidades de organização política dos(as) trabalhadores(as).

A oferta e encaminhamento aos empregos formais são realizados pelo Sistema Nacional de Emprego (SINE). Segundo o Ministério do Trabalho e Emprego (MTE), o objetivo do Sine é reduzir os índices de desemprego, efetuando articulação entre as vagas ofertadas e os 


\section{temporollis}

trabalhadores à procura de emprego. Essa tentativa é atravessada pela própria contradição capital/trabalho, a qual coloca os(as) trabaIhadores(as) em condição desfavorável no processo de negocioação da venda de sua força de trabalho. A imposição da venda da força de trabalho como alternativa única de sobrevivência é imposta aos trabaIhadores e não à burguersia. Soma-se a isso a reprodução e expansão do exército industrial de reserva que amplia a mais-valia do capital por duas vias, uma é a redução do investimento em capital variável e a outra é o incentivo à concorrência entre os trabalhadores, culminando na redução dos salários dos trabalhadores empregados ao máximo possível. Este último aspecto é evidente em países de economia dependente como o Brasil, que conta com um exército industrial de reserva permenente e vasto (MARINI, 2000; MARX, 2008).

O Governo tem por referência, dentre as políticas de geração de trabalho e renda, o Plano Nacional de Qualificação (PNQ), o qual trata da política voltada para qualificação profissional. De acordo com o MTE,

[...] a política pública de qualificação [...] promove gradativamente a universalização do direito dos trabalhadores à qualificação, com vistas a contribuir para o aumento da probabilidade de obtenção de emprego e trabalho decente e da participação em processos de geração de trabalho e renda [...]. (BRASIL, 2015b).

Esta política está organizada mediante os denominados Planos Territoriais, que se referem a convênios do MTE com municípios, estados e/ou entidades sem fins lucrativos. É composta também por Projetos Especiais, os quais são realizados mediante parcerias com os movimentos sociais e organizações não governamentais. Há ainda os Planos Setoriais que ocorrem através de parcerias do MTE com os sindicatos, empresas, movimentos sociais, governos estaduais e/ou muncipais.

A política de qualificação, de acordo com os relatórios do governo, deve ser constituída de elementos que ultrapassem o caráter meramente técnico de sua função, deve garantir a formação de "capital humano". A qualificação profissional deve estar atrelada a perspectiva de construção social do conhecimento, deve obter caráter fundamentalmente pedagógico e instigar o exercício da cidadania e democracia no mundo do trabalho, conforme previsto na PNQ (BRASIL, 2003). 


\section{tempordils}

Cabe destacar que a política de qualificação em referência possui, enquanto função precípua, o papel de qualificar e requalificar a força de trabalho no intuito de inseri-la no mercado de trabalho. Perpassa aqui a teoria do capital humano, devido ao entendimento de que a qualificação profissional é caminho não apenas para o crescimento individual, mas para o crescimento do país. Os valores fundantes dessa política estão na base do capitalismo no estágio atual, sustentados pela perspectiva da igualdade de oportunidades e não de acesso, de construir condições para que a competição individual no mercado de trabalho seja resguardada e o acesso aos espaços seja conquistado, na perspectiva do mérito. Vale destacar que, a qualificação profissional tem por fim inserir os trabalhadores recém-qualificados no mercado de trabalho, em atividades formais ou informais de trabalho, sendo que, contraditoriamente, o capital tem por tendência reduzir o capital variável e ampliar o capital constante no processo produtivo, reproduzindo e ampliando o exército industrial de reserva, que no contexto atual abarca cada vez mais trabalhadores(as).

Dentre os Programas Especiais de Qualificação estão as formações voltadas para os trabalhadores que desenvolvem atividades em cooperativas, em grupos produtivos, "independentes" do funcionamento regular do mercado, tidos também como autogestionários. A denominada Economia Solidária é outra frente incentivada pelo governo atual enquanto alternativa ao desemprego.

De acordo com o Ministério do Trabalho e Emprego,

Economia Solidária é um jeito diferente de produzir, vender, comprar e trocar o que é preciso para viver. Sem explorar os outros, sem querer levar vantagem, sem destruir o ambiente. Cooperando, fortalecendo o grupo, cada um pensando no bem de todos e no próprio bem. A economia solidária vem se apresentando, nos últimos anos, como inovadora alternativa de geração de trabalho e renda e uma resposta a favor da inclusão social. Compreende uma diversidade de práticas econômicas e sociais organizadas sob a forma de cooperativas, associações, clubes de troca, empresas autogestionárias, redes de cooperação, entre outras, que realizam atividades de produção de bens, prestação de serviços, finanças solidárias, trocas, comércio justo e consumo solidário (BRASIL, 2015C).

Para alguns autores essa economia popular se apresenta enquanto alternativa distanciada da lógica capitalista do lucro, do con- 


\section{temporollis}

sumo exacerbado, enquanto iniciativa promissora, inclusive, no que tange a ultrapassagem da sociedade capitalista. ${ }^{22}$ Outras reflexões, como Barbosa (2006), partindo da crítica da Economia Política apontam que este é mais um mecanismo utilizado enquanto alternativa de sobrevivência diante de um modo de produção que necessariamente não emprega a todos.

Assim, diante da potencialidade da Economia Solidária, em face do aprofundamento do quadro de desemprego, esta foi elevada à categoria de política pública pelo Governo Lula no ano de 2003. Atualmente, são milhares os empreendimentos como esses, em todo o país, segundo o próprio Ministério do Trabalho em 2014, "[...] produzindo, vendendo, comprando solidariamente, gerando trabalho e renda $[\ldots] . "$

Conforme justifica o próprio Ministério do Trabalho e Emprego, o incentivo aos pequenos e médios negócios, ao empreendedorismo, as cooperativas ou grupos produtivos, dentre outras alternativas que objetivam a geração de renda pela via do setor informal, tem sido priorizadas. Conforme dito anteriormente, o setor informal não é para a maioria que o compõe uma consciente escolha de atuação no mundo do trabalho. A parte dos(as) trabalhadores(as) desse ramo assume as relações de trabalho mais frágeis e flexíveis, são os mais pobres do meio urbano e também rural, de menor renda e de poucos anos de escolaridade. Sendo que, é cada vez maior o grupo de trabaIhadores(as) que entram e saem do mercado de trabalho, devido ao processo de reestruturação produtiva e a rotatividade das relações de trabalho, essa é a contemporânea superpopulação relativa flutuante; há aqueles que estão de fato por opção, vislumbrando garantir meIhor renda; aqueles que acumulam alguma atividade regulamentada de baixa renda com outra atividade informal complementar; aqueles ainda que só têm essa opção de garantir a sobrevivência, a contemporânea superpopulação relativa estagnada. No caso brasileiro, este grupo compõe permanentemente o mercado de trabalho desde o início do processo de industrialização, visto que estamos tratando de um país dependente que tem sua riqueza (produção de mais-valia) apropriada pela burguesia internacional mediante um processo de superexploração do trabalho.

22 Muitos autores têm corroborado dessa ideia como Paul Singer e seus seguidores, com os quais se discorda neste trabalho. 


\section{tempordils}

Em se tratando da Economia Solidária, os exemplos de organização nesse formato englobam, de acordo com Barbosa (2006, p.102) os "[...] catadores de lixo, processadores de material reciclado, artesãos de diversas áreas, trabalhadores de confecção de roupas, oficinas mecânicas, padarias, segmentos diversos de alimentação, pequenas produções agrícolas, leiteira e pecuária [...]." São estes os grupos motivados pelo governo a garantirem a sobrevivência por essa via. Estes grupos possuem precária tecnologia e precário desenvolvimento das forças produtivas, estão atrelados a atividades de comércio e de mercado e, tendem a se tornarem pequenos negócios regulamentados ou se manterem isolados dentro de uma dinâmica de mercado globalizada sob a égide financeira. Essas formas de atuação mantêm o status quo, a exploração do capital sobre o trabalho, e a reprodução da questão social, metamorfoseando suas expressões.

Neste contexto, impera a busca por lucros por aqueles detentores dos meios de produção e também da riqueza. As políticas públicas e sociais conduzidas pelo Governo PT na perspectiva atual, não se desvencilharão dessa linha a ponto de 'por em xeque' sua real defesa e seus compromissos com as elites do país. Segundo Alencar (2008, p.120), as políticas de geração de emprego e renda "[...] articulam-se sob uma lógica em que, à medida que atendem algumas necessidades do trabalho, o fazem, no entanto, subordinadas às requisições e necessidades do capital [...]."

As políticas no campo do trabalho cumprem ainda papel importante na legitimação do Estado. No âmbito da aparência, este aparece como aquele que investe nessa política, que tenta solucionar os problemas advindos do desemprego, que se preocupa e que constrói estratégias. Na essência, o Estado cumpre ainda a função precípua de não apenas defender os interesses das classes dominantes, mas de apaziguar os conflitos entre as classes. Desde o início, tem a política social - mesmo que executada a partir de programas focalizados e meramente compensatórios - o papel de garantir a manutenção da ordem, evitando a propagação de rebeliões e rebeldias, amenizando a luta de classes. No Brasil contemporâneo, soma-se a conformação das políticas sociais à crise do sindicalismo brasileiro e da própria esquerda brasileira, numa tendência ao enfraquecimento da organização dos(as) trabalhadores(as) na luta de classes.

Pode-se perceber, conforme Soares (2002), que o "ajuste neoliberal" no Brasil, implicou em mudanças significativas no contexto 


\section{temporollis}

do trabalho. Deve-se considerar também que a perspectiva ideológica neoliberal tende a desmobilizar os(as) trabalhadores(as), devido, conforme apontado por Antunes (2007), a "heterogeneização, fragmentação e complexificação" dessa classe. Outra agravante no caso brasileiro é o fato de estarmos na quarta gestão governamental oriunda de um partido que historicamente se constituiu enquanto referência no campo da esquerda brasileira e que - diferente do esperado por boa parte de seus membros orgânicos e de seus eleitores - manteve e fortaleceu as prerrogativas neoliberais. Dessa forma, nesse contexto, as políticas sociais na área do trabalho tendem a se reafirmarem enquanto sustentadoras da ordem capitalista, contribuindo para a desarticulação de movimentos de oposição ao capital.

\section{Considerações finais}

Portanto, a lógica que permeia a implementação das políticas de geração de trabalho e renda no Brasil mantém a perspectiva do capital internacional para a América Latina.

Nesse sentido, o aprofundamento da superexploração do trabalho no Brasil, a transferência de mais-valia para os países centrais, conformando o processo de troca desigual; o baixo desenvolvimento das forças produtivas e a perspectiva de Estado neoliberal que aprofunda o conflito capital/trabalho; o processo de flexibilização do trabalho; a ampliação do exército industrial de reserva e a incorporação de novos grupos de trabalhadores(as) as três formas de superpopulação relativa; as novas manifestações e expressões da "questão social" daí decorrentes; e, o aumento da pobreza absoluta e, especialmente, relativa, no caso brasileiro, estão remetendo os(as) trabalhadores(as) a condições de vida e de trabalho cada vez mais extenuantes.

As políticas de geração de trabalho e renda implementadas atualmente no país e imersas neste contexto, aparentemente, buscam enfrentá-lo. Contudo, essencialmente, considerando a natureza dessas políticas, estas buscam legitimar o Estado e o atual Governo brasileiro e, muito pouco, impactam nas condições de vida e trabaIho da população brasileira. Isso porque a maior parte dessas políticas está destinada ao fortalecimento das ocupações nos setores informais da economia, em face da concessão de crédito para iniciar ou investir em atividades por conta própria ou voltadas ao auto emprego. A política de qualificação também não se destina ao encaminhamento de trabalhadores(as) a empregos formais de trabalho necessariamen- 
te, sendo fortalecida por cursos e atividades também destinadas a inserção no mercado informal.

No ano de 2015, diversas novas medidas no campo do trabalho estão sendo implementadas com a intenção de conter as demissões em massa advindas do aprofundamento da crise no país. A perspectiva é de que haja até 1,2 milhões de demissões até o fim do ano de 2015, sendo que apenas nos dois primeiros meses do ano foram fechados mais de 84.000 postos de trabalho, segundo o IBGE. As principais medidas lançadas pelo Governo diante da crise foram: a aprovação do Programa de Proteção ao Emprego, o qual institui uma redução da jornada de trabalho em até $30 \%$, havendo uma perda salarial real de $15 \%$, pois os outros $15 \%$ são pagos pelo Governo através de recursos do FAT; e a Bolsa de qualificação ou layoff, que encerra temporariamente os contratos de trabalho por até cinco meses, sendo que o pagamento dos(as) trabalhadores(as) neste período ocorre através do seguro desemprego, devendo os mesmos realizar cursos de qualificação. $O$ layoff costuma ser a última medida adotada pelas empresas antes de efetivar as demissões. É nítido que o pagamento pelas perdas do capital em período de crise recai sobre os(as) trabalhadores(as), pois são estes que mantém o FAT e que sofrem as consequências do desemprego e de sua ameaça.

Somam-se a essas estratégias àquelas que vêm sendo implementadas pelas próprias empresas como: férias coletivas, redução das jornadas de trabalho e das semanas, além das próprias demissões.

A perda de direitos também se manifestou em alterações recentes na legislação do trabalho. O Projeto de Lei n. 4.330/2004 sobre a Terceirização, que já possuía nove anos, é conduzido à aprovação no início de 2015, segue em trâmite e objetiva autorizar a terceirização de todas as atividades de qualquer empresa, alterando a Súmula 331 do Tribunal Superior do Trabalho (TST). Também houve modificações nos benefícios previdenciários, como Abono Salarial, Seguro Desemprego, Auxílio Doença, entre outros, conforme previsto nas Medidas Provisórias n. 664 e n. 665, de 2015. Todas as alterações indicam a restrição do acesso a esses benefícios, e/ ou focalizá-los em um grupo cada vez mais reduzido de trabalhadores(as).

Diante do enfraquecimento da luta de classes em favor dos(as) trabalhadores(as) que se iniciou ainda na década de 1990 no Brasil, recentemente vivenciamos uma retração considerável na organiza- 


\section{temporollis}

ção política da esquerda do país, mediante o que também tem sido denominado de crise política e partidária, agravada neste contexto de 2015. Tal fato tem sido marcado por uma ampliação da oposição política ao Governo PT, oposição esta que soma as elites às classes médias brasileiras, fundamentalmente, sendo que os(as) trabalhadores(as) mais pobres e aqueles que se propõem a estar, organizar e lutar no campo da esquerda deste país têm pela frente inúmeros desafios.

Referências

ALENCAR, M. M. T. As políticas públicas de emprego e renda no Brasil: do "nacional-desenvolvimentismo" ao "nacional-empreendedorismo". In: ALMEIDA, M. H. T. de; BEHRING, E. R. (Orgs.). Trabalho e seguridade social percursos e dilemas. Rio de Janeiro: Cortez, 2008.

ANTUNES, R. Adeus ao trabalho? um ensaio sobre as metamorfoses e a centralidade do mundo do trabalho. 2. ed. São Paulo: Cortez, 2007.

BARBOSA, R. N. C. Economia solidária: estratégias de governo no contexto da desregulamentação social do trabalho. In: SILVA, M. O. S; POCHMANN, M.; ANTUNES, R. et al. (Orgs.). Políticas públicas de trabalho e renda no Brasil contemporâneo. São Paulo: Cortez, 2006.

BEHRING, E. R. Brasil em contra reforma: desestruturação do estado e perda de diretos. São Paulo: Cortez, 2003.

BRASIL. Relação Anual de Informações Sociais. Evolução do emprego formal, segundo a RAIS, período de 2003 a 2014. Brasil, 2015a. Disponível em: < http://portal.mte.gov.br/portal-mte/rais/ >. Acesso em: 13 set. 2015 .

- Ministério do Trabalho e Emprego. Programas de Geração de Emprego e Renda. Brasil, 2015b. Disponível em: <http://www.mte. gov.br/proger/oquee.asp>. Acesso em: 1 set. 2015.

. Economia solidária. 2015c. Disponível em: <http://www.mte. gov.br/ecosolidaria/ecosolidaria_oque.asp >. Acesso em: 1set. 2015.

. Programa Nacional do Microcrédito Produtivo Orientado. 2015d. Disponível em: <http://www.mte.gov.br/pnmpo/pnmpo_apresentacao.asp >. Acesso em: 1 set. 2015. 
. Bases de uma nova Política Pública de Formação. Programa Nacional de Qualificação. Brasil, 2003. Disponível em: < http://www. mte.gov.br/pnq/conheca_base.pdf> Acesso em: 1 set. 2015.

CARCANHOLO, R.; NAKATANI, P. O capital especulativo parasitário: uma precisão teórica sobre o capital financeiro, característico da globalização. Ensaios FEE, Porto Alegre, v. 20, n. 1, p. 284-304, jun. 1999.

. et.al. A categoria marxista de trabalho produtivo. In: ENCONTRO NACIONAL DE ECONOMIA POLÍTICA, 12, 2007, São Paulo. Anais..., São Paulo, 2007.

CARVALHO, J. M. de. Cidadania no Brasil o longo caminho. 10. ed. Rio de Janeiro: Civilização Brasileira, 2008.

DIEESE. Departamento Intersindical de Estatísticas e Estudos Socioeconômico. Pesquisa de emprego e desemprego. São Paulo, Departamento Intersindical de Estatísticas e Estudos socioeconômicos, 2014. Disponível em: < http://www.dieese.org.br/analiseped/ped.html>. Acesso em: 13 set. 2014 .

GOUNET, T. Fordismo e toyotismo na civilização do automóvel. São Paulo: Boitempo, 1999.

HARVEY, D. Condição pós-moderna: uma pesquisa sobre as origens da mudança cultural. 16. ed. São Paulo: Loyola, 2007.

IAMAMOTO, M. V. Serviço Social em tempo de capital fetiche: capital financeiro, trabalho e questão social. São Paulo: Cortez, 2008.

IBGE. Instituto Brasileiro de Geografia e Estatística. Indicadores IBGE: pesquisa mensal de emprego. Jul. 2015. Disponível em: < <ftp://ftp. ibge.gov.br/Trabalho_e_Rendimento/Pesquisa_Mensal_de_Emprego/fasciculo_indicadores_ibge/2015/pme_201507pubCompleta.pdf > Acesso em: 13 set. 2015 .

LUKÁCS, G. Os princípios ontológicos fundamentais de Marx. São Paulo: Ciências Humanas, 1979.

MARINI, Ruy Mauro. Dialética da dependência, uma ontologia da obra de Ruy Marini. Petrópolis: Vozes, 2000. 


\section{temporalis}

MARQUES, R. M.; REGO, J. M. (Org.). Economia brasileira. 2. ed. São Paulo: Saraiva, 2003.

MARX, K. O capital: crítica da economia política. 25. ed. Rio Janeiro: Civilização Brasileira, 2008. Livro I, v. 1.

• _ _ São Paulo: Nova Cultura, 1996. Livro I, v. 2.

MÉSZÁROS, I. A crise estrutural do capital. Rio de Janeiro: Boitempo, 2011.

PAULO NETTO, J. Capitalismo monopolista e Serviço Social. 4. ed. São Paulo: Cortez, 2005.

SOARES, L. T. Os custos sociais do ajuste neoliberal na América Latina. 2. ed. São Paulo: Cortez, 2002.

TAVARES, M. A. Os fios invisíveis da produção capitalista: informalidade e precarização do trabalho. São Paulo: Cortez, 2002. 